\title{
Accessibility of Virtual Visits for Urgent Care Among US Hospitals: a Descriptive Analysis
}

J Gen Intern Med 36(7):2184-5

DOI: $10.1007 / \mathrm{s} 11606-020-05888-\mathrm{x}$

(c) Society of General Internal Medicine 2020

\section{INTRODUCTION}

Complex regulations and limited reimbursement have hindered telehealth. ${ }^{1}$ However, increasing experience with telehealth during the COVID-19 crisis represents an opportunity to facilitate its use more generally after this crisis. ${ }^{2}$ While telehealth has the potential to expand access to care, disparities in access are an ongoing concern. ${ }^{3}$ Many hospitals now offer real-time "virtual visits" for common urgent care through their websites, which offer an opportunity to assess the accessibility of a typical telehealth service. ${ }^{4}$

\section{METHODS}

We assembled a geographically representative sample of 170 hospitals in the USA, according to previously published methodology. ${ }^{5}$ In brief, we selected hospitals according to an algorithm that involved gross receipts, geographic diversity, and bed size; at least one hospital in each state was included. Hospitals are often part of multi-hospital systems with web portals for the entire network of hospitals. In our estimation, websites of sampled hospitals represented about 1200 hospitals, one-fifth of all US hospitals.

Many hospitals have begun offering virtual visits for urgent care with real-time connectivity through their websites. We chose to focus on virtual urgent care with both audio and visual connectivity. Hospitals used different names for these services such as "e-visits," "virtual urgent care," and "virtual visits." We included links to primary care visits if the website clearly indicated quick access for urgent care. We excluded other versions of urgent care including online algorithms (e.g., "symptom checkers") or audio-only services.

We examined hospital websites and their virtual visit sites, focusing on three accessibility characteristics: general availability, language accommodations, and affordability. General availability included the presence or absence of virtual visits and relevant exclusions. Navigation started from the main hospital system website, with attempts to proceed logically to virtual urgent care, or "virtual visits." If that failed, a separate search was conducted with the hospital's name and

Received April 16, 2020

Accepted April 28, 2020

Published online May 18, 2020 "virtual visits." We included virtual visits with real-time, audio-visual connectivity for urgent care. Websites were accessed March 23-April 2, 2020.

\section{RESULTS}

Ninety-eight hospitals (58\%) offered virtual visits (see Table 1); however, restrictions were common: About onefifth of virtual visits were not publicly accessible. Even among hospitals with publicly accessible virtual visits, further limitations included geographic limitations (i.e., accessing care across state lines) and exclusions for chronic health conditions. Ease of navigation was variable. Some virtual visit links were advertised on the main page, while others required more thorough searches.

Language accessibility was poor. Among hospitals with virtual visits, $31 \%$ made language accommodations easily identifiable on navigation (usually only Spanish translation). Only 1 hospital clearly noted interpreter options for virtual visits.

Most hospitals charged a flat fee for virtual visits (median charge, \$49). Payment was usually required upfront; no hospital made accommodations for ability to pay (although $16 \%$ temporarily waived fees in relation to COVID-19).

\section{DISCUSSION}

Virtual visits were not easily or equitably accessible; in general, navigation of hospital websites was challenging. Most hospitals required navigation in English, and only one clearly offered interpreter services, which are considered best practice and legally required. Exclusions for new patients or patients with chronic medical conditions suggest that clinicians and hospitals may be hesitant to care for new or complex patients without physical examinations; however, such exclusions favor healthier, insured patients. The requirement of up-front payment, albeit modest, reinforces bias towards higher income patients.

Other limitations such as the reading level of websites and internet bandwidth requirements were not assessed and deserve further investigation. Broadband access is a welldescribed limitation for rural and low-income communities. ${ }^{6}$

The pattern that emerges in this survey is all too familiar: Access favors generally healthy, well-off, English-speaking patients. We suspect this pattern results from a combination of telehealth policy constraints (e.g., limited reimbursement) and neglect on the part of clinicians and hospitals. 
Table 1 General Accessibility Characteristics of Virtual Visits $(n=98)$ Among Sampled Hospitals

\begin{tabular}{|c|c|c|}
\hline \multirow{5}{*}{ Language Accommodations } & Accessible to general public ${ }^{*}$ & $79(81 \%)$ \\
\hline & No geographic limitations ${ }^{\dagger}$ & $67(68 \%)$ \\
\hline & Chronic conditions excluded ${ }^{*}$ & See footnote \\
\hline & Language support evident ${ }^{\S}$ & $30(31 \%)$ \\
\hline & Clearly included interpreter services & $1(1 \%)$ \\
\hline \multirow[t]{2}{*}{ Cost } & Charges transparent & $72(73 \%)$ \\
\hline & Accommodations for low income ${ }^{\|}$ & 0 \\
\hline
\end{tabular}

*Restrictions included the following: access only for "established" patients, exclusion of patients on federal insurance programs, and requirement to purchase additional telehealth equipment

Fenerally, geographic limitations were state-based, requiring the patient to be physically located in a given state at the time of the visit t Some websites alluded directly or indirectly to excluding patients with chronic conditions; however, language was often too vague to allow formal quantitation

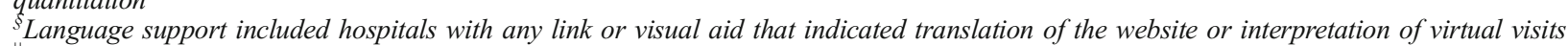

"While none of the hospital websites made general accommodations for income status, 16 hospitals waived fees temporarily due to COVID-19 or specifically for visits related to COVID-19

Nevertheless, legal and moral imperatives compel hospitals to apply best practices regarding accessibility for virtual services. Hospitals do not need to reinvent the wheel; existing resources such as interpreter services and financial counselling could simply be better connected to telehealth services, and government-mandated financial assistance programs could be broadened to include telehealth. Policymakers and healthcare insurers should consider how existing regulations and reimbursement practices reinforce barriers to telehealth. Without such changes, advances in virtual healthcare options may come at the cost of worsening health inequities.

Christopher W. Goodman, MD

Allan S. Brett, MD

Department of Medicine, University of South Carolina School of Medicine,

2 Medical Park, Suite 502, Columbia, SC 29203, USA

Corresponding Author: Christopher W. Goodman, MD; Department of Medicine, University of South Carolina School of Medicine 2 Medical Park, Suite 502, Columbia, SC 29203, USA (e-mail: christopher.goodman@uscmed.sc.edu).

\section{REFERENCES}

1. Daniel H, Sulmasy LS, for the Health and Public Policy Committee of the American College of Physicians. Policy recommendations to guide the use of telemedicine in primary care settings: an American College of Physicians position paper. Ann Intern Med. 2015;163:787-789. DOI: https://doi.org/ 10.7326/M15-0498.

2. Hollander JE, Carr BG. Virtually perfect? Telemedicine for COVID-19. N Engl J Med [published online ahead of print March 11 2020]. DOI: https:// doi.org/10.1056/NEJMp2003539.

3. Dorsey ER, Topol EJ. Telemedicine 2020 and the next decade. Lancet. 2020;395(10227):859. DOI: https://doi.org/10.1016/S0140-6736(20) 30424-4.

4. Duffy S, Lee TH. In-person health care as option B. N Engl J Med. 2018;378:104-106. DOI: https://doi.org/10.1056/NEJMp1710735.

5. Goodman CW, Flanigan A, Probst JC, Brett AS. Charity care characteristics and expenditures among US tax-exempt hospitals in 2016. Am J Public Health. 2020;110:492-498. DOI: https://doi.org/10.2105/AJPH. 2019.305522.

6. Bauerly BC, McCord RF, Hulkower R, Pepin D. Broadband access as a public health issue: the role of law in expanding broadband access and connecting underserved communities for better health outcomes. J Law Med Ethics. 2019;47(2):39-42. DOI: https://doi.org/10.1177/ 1073110519857314.

Publisher's Note: Springer Nature remains neutral with regard to jurisdictional claims in published maps and institutional affiliations. 